medgen $2018 \cdot 30: 448-460$

https://doi.org/10.1007/s11825-018-0226-y

Online publiziert: 19. Dezember 2018

(C) Der/die Autor(en) 2018

CrossMark

\author{
Anne Kosfeld ${ }^{1}$ Helge Martens ${ }^{1} \cdot$ Imke Hennies ${ }^{2}$. Dieter Haffner ${ }^{2}$. \\ Ruthild G. Weber ${ }^{1}$ \\ ${ }^{1}$ Institut für Humangenetik, Medizinische Hochschule Hannover, Hannover, Deutschland \\ ${ }^{2}$ Klinik für Pädiatrische Nieren-, Leber- und Stoffwechselerkrankungen, Medizinische Hochschule \\ Hannover, Hannover, Deutschland
}

\title{
Kongenitale Anomalien der Nieren und ableitenden Harnwege (CAKUT)
}

Anwendung von exom- und genomweiten Screeningverfahren hat in den letzten Jahren beträchtlich dazu beigetragen, die genetischen CAKUT-Ursachen weiter aufzuklären. Dennoch stehen wir erst am Anfang dieses Erkenntnisprozesses.

\section{Die CAKUT-Phänotypen: Entstehung, Häufigkeit, Diagnostik, Therapie, Verlauf}

Die verschiedenen CAKUT-Phänotypen entstehen in unterschiedlichen Stadien der Nierenentwicklung. Die Entwicklungsstadien der endgültigen Niere (Metanephros) sind (i) die Induktion der Ureterknospe aus dem Wolff'schen

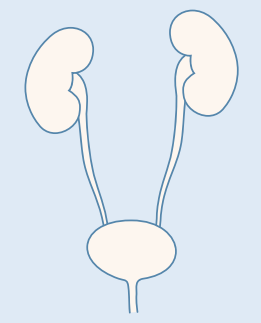

Normale Nieren

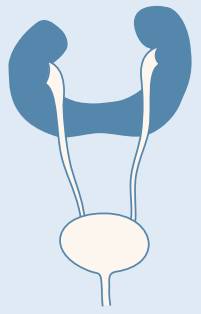

Hufeisenniere 1:400

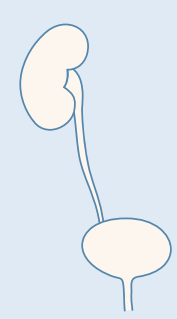

Nierenagenesie Einseitig: 1:1.000 Beidseitig: 1:4.0001:10.000

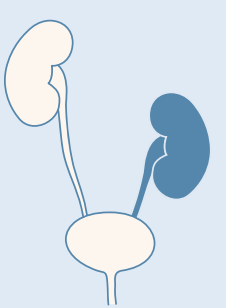

Beckenniere 1:2.000-1:3.000

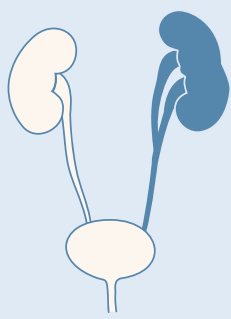

Doppelniere 1:25-1:100

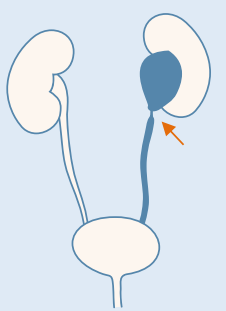

Ureteropelvine

Stenose

1:125-1:500

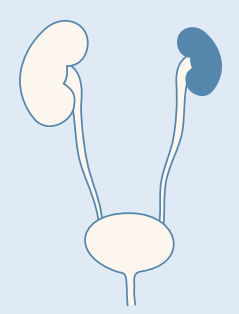

Nierenhypoplasie Einseitig: 1:500

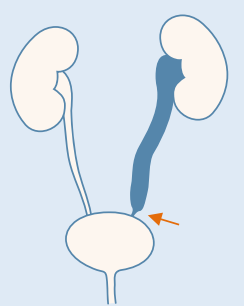

Uretermündungsstenose 1:3.000

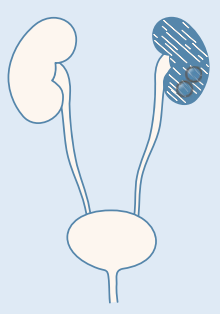

Nierendysplasie Einseitig: 1:1.000 Beidseitig: 1:9.000

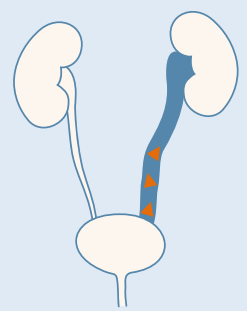

Vesikoureteraler Reflux 1:100

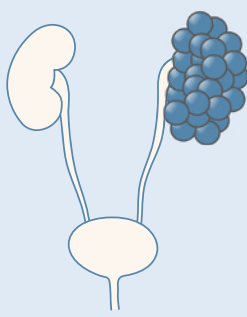

Multizystischdysplastische Niere 1:4.000

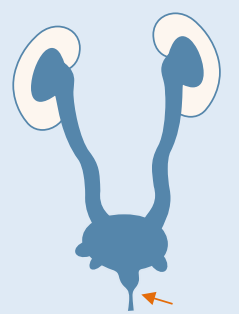

Harnröhrenklappen 1:5.000-1:8.000

Abb. 1 ॥ Schematische Darstellung einzelner CAKUT (Congenital Anomalies of the Kidney and Urinary Tract)-Phänotypen. In schwarzer Schrift sind ungefähre Häufigkeiten bei Neugeborenen nach Stein et al. [80], für die Nierenhypoplasie bei Autopsiefällen nach Schärer [72] und für die Nierendysplasie bei Neugeborenen nach Caiulo et al. [9] angegeben. Häufig treten die unterschiedlichen Anomalien kombiniert auf. Der Schweregrad kann stark variieren 

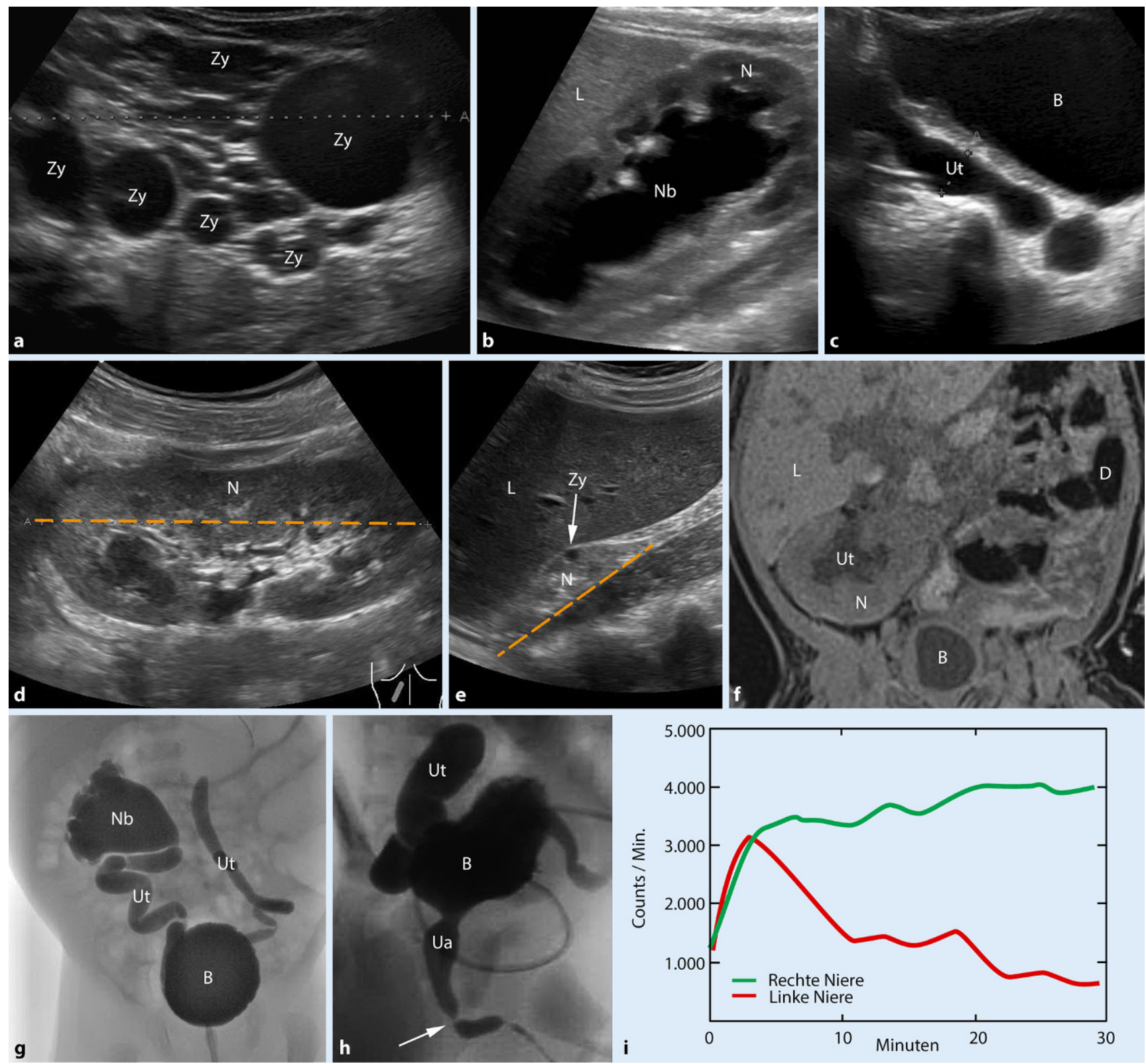

Abb. 2 ॥ Verschiedene CAKUT-Phänotypen in der radiologischen Diagnostik. a MCDK links (Sonographie).

b HTS III-IV bei UPJO rechts (Sonographie).

c Harnblase im Längsschnitt mit retrovesikalem Megaureter rechts (Sonographie).

d, e Normale Niere links und hypodysplastische Niere rechts des gleichen Patienten (Sonographie).

f Nierenagenesie links und Malrotation mit Hydronephrose rechts (MRT).

g VUR ${ }^{\circ}$ V rechts und elongierter Ureter ohne Kelchsystem bei MCDK links (MCU).

h Beidseitiger VUR ${ }^{\circ} V$ mit Urethralklappen (Pfeil), MCU.

i Fixierte UPJO rechts (Nierenfunktionsszintigraphie).

B Blase, CAKUT Congenital Anomalies of the Kidney and Urinary Tract, D Darm, HTS Harntransportstörungen, L Leber,

MCDK multizystisch-dysplastische Niere, MCU Miktionszystourethrographie, MRT Magnetresonanztomographie, N Niere,

Nb Nierenbecken, Ua Urethra, UPJO ureteropelvine Stenose, Ut Ureter, VUR vesikoureteraler Reflux, Zy Zyste 
Gang und dessen Interaktion mit dem metanephrogenen Mesenchym, (ii) das Wachstum dieser Strukturen, (iii) die Nephrogenese an den Spitzen der sich verzweigenden Ureterknospe sowie (iv) die Nephronstrukturierung in Glomerulus und unterschiedliche Tubulussegmente [73]. Durch eine Störung der Ureterknospeninduktion kann es zu einer fehlenden Niere (Nierenagenesie) oder zu einer Dopplungsfehlbildung von Niere und Ureter kommen. Ist das Wachstum von Ureter und metanephrogenem Mesenchym gestört, kann sich eine Nierenhypoplasie (verkleinerte Niere mit verminderter Anzahl an normalen Nephronen) entwickeln. Eine Nierendysplasie, bei der die Niere abnormale Strukturen wie undifferenziertes Gewebe und/oder Zysten enthält, resultiert aus einer Störung bei der Nephrogenese, wobei die multizystisch-dysplastische Niere (MCDK, funktionslose Niere mit großzystischer Malformation) eine besonders ausgeprägte Form und die Nierenhypodysplasie eine häufige Mischform darstellt. Weitere CAKUTPhänotypen umfassen Verschmelzungsund Lageanomalien der Nieren, wie die Hufeisenniere und Nierenektopie, sowie obstruktive Uropathien, wie die ureteropelvine Stenose (UPJO), Uretermündungsstenose (UVJO) mit primärem Megaureter und Harnröhrenklappen (PUV) mit sekundären Megaureteren, und den vesikoureteralen Reflux (VUR), die mit einer Hydronephrose einhergehen können (• Abb. 1; [26, 73, 80]).

Alle CAKUT Anomalien zusammen haben eine Prävalenz in der Größenordnung von 3-9 pro 1000 Lebendgeburten $[60,61,81]$ und machen etwa $15-30 \%$ aller pränatal diagnostizierten Fehlbildungen aus [17, 61, 73, 86]. Dabei sind schwerwiegende beidseitige CAKUTPhänotypen bei Neugeborenen seltener, weil betroffene Feten (z. B. mit bilateraler Nierenagenesie oder MCDK) intrauterin versterben können. Phänotypen hingegen, die die intrauterine Entwicklung nicht wesentlich beeinflussen, weil sie asymptomatisch bleiben (z. B. Doppelanlage, Hufeisenniere, unilaterale CAKUTFormen), kommen bei Neugeborenen häufiger vor (• Abb. 1; [26, 80]). Oftmals treten bei CAKUT-Patienten verschie-

medgen 2018 - 30:448-460 https://doi.org/10.1007/s11825-018-0226-y

(c) Der/die Autor(en) 2018

\section{A. Kosfeld · H. Martens $\cdot$ I. Hennies $\cdot$ D. Haffner $\cdot$ R. G. Weber \\ Kongenitale Anomalien der Nieren und ableitenden Harnwege (CAKUT)}

\section{Zusammenfassung}

Der Begriff CAKUT (Congenital Anomalies of the Kidney and Urinary Tract) bezeichnet diverse angeborene Fehlbildungen der Nieren und ableitenden Harnwege. Da alle CAKUT-Phänotypen zusammengenommen etwa 15-30\% aller pränatal diagnostizierten Fehlbildungen ausmachen und etwa $40 \%$ der Fälle mit terminalem Nierenversagen bei Kindern und Jugendlichen verursachen, sind diese Anomalien epidemiologisch hochrelevant. Die Diagnosestellung erfolgt mit radiologischen Verfahren, insbesondere mit Ultraschall, wobei bei vielen Patienten eine Kombination verschiedener CAKUTPhänotypen nachgewiesen wird. CAKUT tritt zu etwa $85 \%$ sporadisch auf, zu etwa $15 \%$ familiär. Das Vererbungsmuster ist häufig dominant, kann aber auch rezessiv sein. CAKUT kann isoliert auftreten, aber auch als Teil einer syndromalen Erkrankung. Variable Expressivität und inkomplette Penetranz sind bei CAKUT häufig. CAKUT ist genetisch sehr heterogen. Im Mausmodell wurden bislang über 180 CAKUT-assoziierte Gene beschrieben. Da Mutationen in den etwa 50 bisher bekannten humanen CAKUT-Genen nur ca. $20 \%$ der CAKUT-Fälle erklären und sich verschiedene chromosomale Aberrationen wie Mikrodeletionen in weiteren ca. $15 \%$ der Patienten insbesondere mit syndromalen CAKUT finden, sind exom-/genomweite Screeningverfahren für die Aufklärung genetischer CAKUT-Ursachen besonders geeignet. Bei sporadischen Fällen ist eine Trio-basierte Analyse der Exome/Genome von Patienten-Eltern-Trios zur Identifizierung von De-novo-Aberrationen und biallelischen Varianten vielversprechend. Eine Abklärung der genetischen Ursache ist für die Präzisierung von Wiederholungsrisiken sowie eine gezielte Untersuchung von CAKUT-Patienten im Hinblick auf extrarenale Phänotypen von klinischer Bedeutung.

Schlüsselwörter

Nephrologie · Diagnostik · Genetische Heterogenität · Exom-/genomweite Screeningverfahren - Extrarenale Phänotypen

\section{Congenital anomalies of the kidney and urinary tract (CAKUT)}

\section{Abstract}

The term CAKUT comprises various congenital anomalies of the kidney and urinary tract. Taken together, CAKUT phenotypes account for approximately $15-30 \%$ of all prenatally detected congenital malformations, and cause around $40 \%$ of cases with endstage kidney disease in children and adolescents; thus, these anomalies are of great epidemiological relevance. Diagnosis is made using radiological techniques, in particular ultrasound, which establishes a combination of various CAKUT phenotypes in many patients. CAKUT occur sporadically in around $85 \%$ of patients, whereas around $15 \%$ of cases are familial. The inheritance pattern is frequently dominant, but it can also be recessive. CAKUT can occur as an isolated malformation or as part of a syndromic disorder. Variable expressivity and incomplete penetrance are frequent in CAKUT. CAKUT are genetically highly heterogeneous. Using mouse models, more than 180 CAKUTassociated genes have been described to date. As mutations in the approximately 50 human CAKUT genes known so far account for only around $20 \%$ of cases, and various chromosomal aberrations such as microdeletions are causative in another approximately $15 \%$ of patients, particularly in those with syndromic CAKUT, exomeand genome-wide screening methods are especially suitable for identifying the genetic causes of CAKUT. In sporadic cases, trio-based analysis of exomes/genomes of patientparent trios to detect de novo aberrations and biallelic genomic variants seems particularly promising. It is of clinical significance to resolve the genetic causes of CAKUT to predict the risk of recurrence and to guide evaluation of CAKUT patients with regard to extrarenal phenotypes.

\section{Keywords}

Nephrology · Diagnostics - Genetic heterogeneity · Exome-/genome-wide screening methods - Extrarenal phenotypes 
Tab. 1 Humane Gene, deren Veränderung in $\geq 3$ Familien mit CAKUT (Congenital Anomalies of the Kidney and Urinary Tract) assoziiert wurde

\begin{tabular}{|c|c|c|c|c|c|}
\hline Gen (HGNC) & Protein (HGNC) & OMIM & Phänotyp & Vererbung & Literatur \\
\hline$A C E$ & Angiotensin I converting enzyme & 106180 & Renale tubuläre Dysgenesie & $A R$ & $\begin{array}{l}\text { Gribouval et al. [22] } \\
\text { Gribouval et al. [23] }\end{array}$ \\
\hline AGT & Angiotensinogen & 106150 & Renale tubuläre Dysgenesie & $A R$ & $\begin{array}{l}\text { Gribouval et al. [22] } \\
\text { Gribouval et al. [23] }\end{array}$ \\
\hline AGTR1 & Angiotensin II receptor type 1 & 106165 & Renale tubuläre Dysgenesie & $A R$ & $\begin{array}{l}\text { Gribouval et al. [22] } \\
\text { Gribouval et al. [23] }\end{array}$ \\
\hline ANOS1 & Anosmin 1 & 300836 & $\begin{array}{l}\text { Kallmann-Syndrom, } \\
\text { nicht syndromale Nierenagenesie }\end{array}$ & $\mathrm{XL}$ & $\begin{array}{l}\text { Hardelin et al. [28] } \\
\text { Heidet et al. [31] }\end{array}$ \\
\hline BICC1 & BicC family RNA binding protein 1 & 614295 & CAKUT & $A D$ & $\begin{array}{l}\text { Kraus et al. [47] } \\
\text { Heidet et al. [31] }\end{array}$ \\
\hline BMP4 & Bone morphogenetic protein 4 & 112262 & CAKUT & $A D$ & $\begin{array}{l}\text { Weber et al. [93] } \\
\text { Tabatabaeifar et al. [83] }\end{array}$ \\
\hline$C D C 5 L$ & Cell division cycle 5 like & 602868 & CAKUT & $A D$ & $\begin{array}{l}\text { Groenen et al. [24] } \\
\text { Hwang et al. [35] } \\
\text { Heidet et al. [31] }\end{array}$ \\
\hline CHD1L & $\begin{array}{l}\text { Chromodomain helicase DNA } \\
\text { binding protein } 1 \text { like }\end{array}$ & 613039 & CAKUT & $A D$ & $\begin{array}{l}\text { Brockschmidt et al. [7] } \\
\text { Hwang et al. [35] } \\
\text { Nicolaou et al. [59] } \\
\text { Heidet et al. [31] }\end{array}$ \\
\hline CRKL & $\begin{array}{l}\text { CRK like proto-oncogene, adaptor } \\
\text { protein }\end{array}$ & 602007 & CAKUT & $A D$ & Lopez-Rivera et al. [52] \\
\hline DSTYK & $\begin{array}{l}\text { Dual serine/threonine and tyrosi- } \\
\text { ne protein kinase }\end{array}$ & 612666 & CAKUT & $A D$ & $\begin{array}{l}\text { Sanna-Cherchi et al. [68] } \\
\text { Wu et al. [95] }\end{array}$ \\
\hline EYA1 & $\begin{array}{l}\text { EYA transcriptional coactivator } \\
\text { and phosphatase } 1\end{array}$ & 601653 & Branchiootorenales Syndrom & $A D$ & $\begin{array}{l}\text { Abdelhak et al. [1] } \\
\text { Hwang et al. [35] } \\
\text { Heidet et al. [31] }\end{array}$ \\
\hline FAT4 & FAT atypical cadherin 4 & 612411 & Van Maldergem syndrome 2, CAKUT & $A R / A D$ & $\begin{array}{l}\text { Nicolaou et al. [59] } \\
\text { Van der Ven et al. [85] }\end{array}$ \\
\hline FOXP1 & Forkhead box P1 & 605515 & Syndromale CAKUT & $A D$ & Bekheirnia et al. [5] \\
\hline FRAS1 & $\begin{array}{l}\text { Fraser extracellular matrix com- } \\
\text { plex subunit } 1\end{array}$ & 607830 & Fraser-Syndrom 1, nicht syndromale CAKUT & $A R / A D$ & $\begin{array}{l}\text { McGregor et al. [55] } \\
\text { Saisawat et al. [65] } \\
\text { Kohl et al. [42] }\end{array}$ \\
\hline FREM1 & $\begin{array}{l}\text { FRAS1 related extracellular matrix } \\
\text { protein } 1\end{array}$ & 608944 & $\begin{array}{l}\text { Bifide Nase mit/ohne anorektale und renale } \\
\text { Anomalien, nicht syndromale CAKUT }\end{array}$ & $A R$ & $\begin{array}{l}\text { Alazami et al. [4] } \\
\text { Kohl et al. [42] }\end{array}$ \\
\hline FREM2 & $\begin{array}{l}\text { FRAS1 related extracellular matrix } \\
\text { protein } 2\end{array}$ & 608945 & Fraser-Syndrom 2, nicht syndromale CAKUT & $A R / A D$ & $\begin{array}{l}\text { Jadeja et al. [37] } \\
\text { Saisawat et al. [65] } \\
\text { Kohl et al. [42] }\end{array}$ \\
\hline GATA3 & GATA binding protein 3 & 131320 & $\begin{array}{l}\text { Hypoparathyreoidismus, Schwerhörigkeit, } \\
\text { Nierenanomalien, nicht syndromale CAKUT }\end{array}$ & $A D$ & $\begin{array}{l}\text { Van Esch et al. [87] } \\
\text { Hwang et al. [35] } \\
\text { Heidet et al. [31] }\end{array}$ \\
\hline GLI3 & GLI family zinc finger 3 & 165240 & $\begin{array}{l}\text { Pallister-Hall-Syndrom (teilweise mit CAKUT), } \\
\text { CAKUT }\end{array}$ & $A D$ & $\begin{array}{l}\text { Johnston et al. [39] } \\
\text { Nicolaou et al. [59] } \\
\text { Sanna-Cherchi et al. [69] }\end{array}$ \\
\hline GREB1L & $\begin{array}{l}\text { GREB1 like retinoic acid receptor } \\
\text { coactivator }\end{array}$ & 617782 & CAKUT, insbesondere Nierenagenesie & $A D$ & $\begin{array}{l}\text { Brophy et al. [8] } \\
\text { De Tomasi et al. [14] } \\
\text { Sanna-Cherchi et al. [69] } \\
\text { Rasmussen et al. [62] }\end{array}$ \\
\hline GRIP1 & $\begin{array}{l}\text { Glutamate receptor interacting } \\
\text { protein } 1\end{array}$ & 604597 & Fraser-Syndrom 3, CAKUT & $A R / A D$ & $\begin{array}{l}\text { Kohl et al. [42] } \\
\text { Nicolaou et al. [59] }\end{array}$ \\
\hline HNF1B & HNF1 homeobox B & 189907 & $\begin{array}{l}\text { Renale Zysten und Diabetes-Syndrom, } \\
\text { geringgradig syndromale CAKUT }\end{array}$ & $A D$ & $\begin{array}{l}\text { Horikawa et al. [32] } \\
\text { Ulinski et al. [84] } \\
\text { Heidet et al. [30] } \\
\text { Heidet et al. [31] }\end{array}$ \\
\hline HPSE2 & Heparanase 2 (inactive) & 613469 & $\begin{array}{l}\text { Urofaziales (Ochoa)-Syndrom, } \\
\text { syndromale CAKUT }\end{array}$ & $A R$ & $\begin{array}{l}\text { Daly et al. [13] } \\
\text { Vivante et al. [91] }\end{array}$ \\
\hline ITGA8 & Integrin subunit alpha 8 & 604063 & CAKUT, insbesondere Nierenagenesie & $A R$ & $\begin{array}{l}\text { Humbert et al. [34] } \\
\text { Kohl et al. [42] }\end{array}$ \\
\hline
\end{tabular}


Tab. 1 (Fortsetzung)

\begin{tabular}{|c|c|c|c|c|c|}
\hline Gen (HGNC) & Protein (HGNC) & OMIM & Phänotyp & Vererbung & Literatur \\
\hline KIF14 & Kinesin family member 14 & 611279 & CAKUT, Mikrozephalie, Gehirnfehlbildungen & $A R / A D$ & $\begin{array}{l}\text { Filges et al. [16] } \\
\text { Heidet et al. [31] }\end{array}$ \\
\hline LIFR & LIF receptor alpha & 151443 & CAKUT & $A D$ & Kosfeld et al. [46] \\
\hline LRIG2 & $\begin{array}{l}\text { Leucine rich repeats and immuno- } \\
\text { globulin like domains } 2\end{array}$ & 608869 & $\begin{array}{l}\text { Urofaziales (Ochoa)-Syndrom } 2 \text { mit CAKUT } \\
\text { (insbesondere Blasenstörung mit VUR) }\end{array}$ & AR & Stuart et al. [82] \\
\hline LRP4 & LDL receptor related protein 4 & 604270 & Cenani-Lenz-Syndrom mit CAKUT, CAKUT & $\mathrm{AR} / \mathrm{AD}$ & $\begin{array}{l}\text { Khan et al. [40] } \\
\text { Nicolaou et al. [59] } \\
\text { Afzal et al. [2] } \\
\text { Stals et al. [79] }\end{array}$ \\
\hline MUC1 & Mucin 1 , cell surface associated & 158340 & Medulläre zystische Nierenkrankheit Typ 1 & $A D$ & Kirby et al. [41] \\
\hline NEK8 & NIMA related kinase 8 & 609799 & $\begin{array}{l}\text { Renal-hepato-pankreatische Dysplasie } 2, \\
\text { syndromale zystische Nierendysplasie }\end{array}$ & AR & $\begin{array}{l}\text { Frank et al. [18] } \\
\text { Grampa et al. [21] } \\
\text { Lei et al. [49] }\end{array}$ \\
\hline PAX2 & Paired box 2 & 167409 & $\begin{array}{l}\text { Renales-Kolobom-Syndrom, } \\
\text { nicht syndromale CAKUT }\end{array}$ & $A D$ & $\begin{array}{l}\text { Sanyanusin et al. [71] } \\
\text { Negrisolo et al. [56] } \\
\text { Hwang et al. [35] } \\
\text { Nicolaou et al. [59] } \\
\text { Heidet et al. [31] }\end{array}$ \\
\hline PBX1 & PBX homeobox 1 & 176310 & $\begin{array}{l}\text { CAKUT mit oder ohne Schwerhörigkeit, } \\
\text { faziale und skelettale Auffälligkeiten, } \\
\text { Entwicklungsverzögerung }\end{array}$ & $A D$ & $\begin{array}{l}\text { Le Tanno et al. [48] } \\
\text { Heidet et al. [31] } \\
\text { Riedhammer et al. [64] }\end{array}$ \\
\hline REN & Renin & 179820 & Renale tubuläre Dysgenesie & $A R$ & $\begin{array}{l}\text { Gribouval et al. [22] } \\
\text { Gribouval et al. [23] }\end{array}$ \\
\hline RET & Ret proto-oncogene & 164761 & CAKUT, insbesondere Nierenagenesie & $A D$ & $\begin{array}{l}\text { Skinner et al. [78] } \\
\text { Hwang et al. [35] } \\
\text { Heidet et al. [31] }\end{array}$ \\
\hline ROBO1 & Roundabout guidance receptor 1 & 602430 & Syndromale Nierenagenesie, CAKUT & $A R / A D$ & $\begin{array}{l}\text { Nicolaou et al. [59] } \\
\text { Heidet et al. [31] } \\
\text { Rasmussen et al. [62] }\end{array}$ \\
\hline $\mathrm{ROBO2}$ & Roundabout guidance receptor 2 & 602431 & CAKUT & $A D$ & $\begin{array}{l}\text { Lu et al. [53] } \\
\text { Bertoli-Avella et al. [6] } \\
\text { Hwang et al. [35] } \\
\text { Elahi et al. [15] }\end{array}$ \\
\hline SALL1 & Spalt like transcription factor 1 & 602218 & $\begin{array}{l}\text { Townes-Brocks-Syndrom, } \\
\text { geringgradig syndromale CAKUT }\end{array}$ & $A D$ & $\begin{array}{l}\text { Kohlhase et al. [43] } \\
\text { Hwang et al. [35] } \\
\text { Heidet et al. [31] }\end{array}$ \\
\hline SIX2 & SIX homeobox 2 & 604994 & CAKUT & $A D$ & $\begin{array}{l}\text { Weber et al. [93] } \\
\text { Hwang et al. [35] }\end{array}$ \\
\hline SIX5 & SIX homeobox 5 & 600963 & $\begin{array}{l}\text { Branchiootorenales Syndrom 2, } \\
\text { nicht syndromale CAKUT }\end{array}$ & $A D$ & $\begin{array}{l}\text { Hoskins et al. [33] } \\
\text { Hwang et al. [35] } \\
\text { Sanna-Cherchi et al. [69] }\end{array}$ \\
\hline SLIT2 & Slit guidance ligand 2 & 603746 & CAKUT & $A D$ & $\begin{array}{l}\text { Hwang et al. [36] } \\
\text { Rasmussen et al. [62] }\end{array}$ \\
\hline SOX11 & SRY-box 11 & 600898 & CAKUT & $A D$ & Neirijnck et al. [57] \\
\hline sox17 & SRY-box 17 & 610928 & VUR & $A D$ & Gimelli et al. [20] \\
\hline TBC1D1 & TBC1 domain family member 1 & 609850 & CAKUT & $A D$ & $\begin{array}{l}\text { Kosfeld et al. [45] } \\
\text { Heidet et al. [31] }\end{array}$ \\
\hline TBX18 & T-box 18 & 604613 & CAKUT & $A D$ & $\begin{array}{l}\text { Vivante et al. [89] } \\
\text { Heidet et al. [31] }\end{array}$ \\
\hline$T N X B$ & Tenascin XB & 600985 & VUR mit oder ohne Gelenkhypermobilität & $A D$ & $\begin{array}{l}\text { Gbadegesin et al. [19] } \\
\text { Elahi et al. [15] }\end{array}$ \\
\hline TRAP1 & TNF receptor associated protein 1 & 606219 & CAKUT mit und ohne VACTERL-Assoziation & $A R$ & Saisawat et al. [66] \\
\hline$U M O D$ & Uromodulin & 191845 & $\begin{array}{l}\text { Medulläre zystische Nierenkrankheit Typ 2, } \\
\text { CAKUT }\end{array}$ & $A D$ & $\begin{array}{l}\text { Hart et al. [29] } \\
\text { Nicolaou et al. [59] } \\
\text { Lei et al. [49] }\end{array}$ \\
\hline
\end{tabular}




\begin{tabular}{|c|c|c|c|c|c|}
\hline Gen (HGNC) & Protein (HGNC) & OMIM & Phänotyp & Vererbung & Literatur \\
\hline UPK3A & Uroplakin 3A & 611559 & CAKUT & $A D$ & $\begin{array}{l}\text { Jenkins et al. [38] } \\
\text { Schönfelder et al. [77] } \\
\text { Nicolaou et al. [59] }\end{array}$ \\
\hline WNT4 & Wnt family member 4 & 603490 & $\begin{array}{l}\text { SERKAL-Syndrom mit CAKUT, } \\
\text { nicht syndromale CAKUT }\end{array}$ & $A R / A D$ & $\begin{array}{l}\text { Mandel et al. [54] } \\
\text { Vivante et al. [88] } \\
\text { Wu et al. [95] }\end{array}$ \\
\hline
\end{tabular}

dene Phänotypen kombiniert auf. So beschrieben Cascio et al. bei etwa der Hälfte der Patienten mit einseitiger Nierenagenesie weitere Fehlbildungen aus dem CAKUT-Spektrum, meist obstruktive Uropathien oder VUR [10]. Eine typische klinische Präsentation von CAKUT sind rezidivierende Harnwegsinfekte.

Die Diagnose CAKUT wird mit radiologischen Verfahren gestellt. In der Regel wird dazu die Sonographie verwendet, die bereits pränatal Auffälligkeiten nachweisen kann. Dabei werden die Nieren hinsichtlich ihrer Lage, Form, Größe und Morphologie beurteilt; Megaureteren und Harntransportstörungen (HTS) lassen sich ebenfalls nachweisen (• Abb. 2). Auch die Magnetresonanz (MR)-Urographie steht für die anatomische und funktionelle Beurteilung von Nieren und Harntrakt zur Verfügung. Die Miktionszystourethrographie (MCU) stellt die Standardmethode zur Abklärung von VUR und PUV dar. Über eine suprapubische Blasenpunktion oder eine transurethrale Katheterisierung wird die Harnblase mit Kontrastmittel gefüllt und während der Füllungs- und Miktionsphase durchleuchtet. Obwohl die Strahlenbelastung der MCU deutlich reduziert werden konnte, gibt es durch die Miktionsurosonographie (MSU) eine neuere Alternative. Letztere wird zunehmend zur Verlaufskontrolle des VUR eingesetzt, erlaubt es jedoch nicht, die Diagnose PUV zu stellen. Die Nierenfunktionsszintigraphie ermöglicht den Nachweis von funktionsfähigem Nierengewebe sowie die seitengetrennte Beurteilung der Nierenfunktion und der Harnabflussverhältnisse (• Abb. 2).

Eine frühzeitige Diagnosestellung ist wichtig, weil Patienten mit einigen CAKUT-Phänotypen (z. B. mit obstruktiven Uropathien) von einer operativen oder prophylaktischen antibakteriellen Therapie profitieren können. Obwohl eine einseitige renale Agenesie oder Hypodysplasie, meist durch Hypertrophie der Gegenseite, kompensiert werden und ein VUR sich in den ersten Lebensjahren zurückbilden kann, verursachen CAKUT 50-60\% der Fälle mit chronischer Niereninsuffizienz und etwa $40 \%$ des terminalen Nierenversagens im Kindesund Jugendalter [27]. Bei terminalem Nierenversagen kann heutzutage bereits im Säuglingsalter eine Nierenersatztherapie mittels Dialyse (meist als Peritonealdialyse) oder Nierentransplantation (ab einem Körpergewicht von ca. $6 \mathrm{~kg}$ ) durchgeführt werden. Letztere ermöglicht eine nahezu normale somatische und kognitive Entwicklung, soweit diese nicht durch zusätzliche extrarenale Anomalien eingeschränkt ist. Dennoch haben Kinder, die eine Nierenersatztherapie benötigen, im Vergleich zu gleichaltrigen gesunden Kindern ein 30fach erhöhtes Mortalitätsrisiko, hauptsächlich bedingt durch kardiovaskuläre Komplikationen oder Infektionen [25]. Bei syndromalen CAKUT-Patienten können genetisch bedingte zusätzliche extrarenale Fehlbildungen die Prognose mitbeeinflussen.

\section{Genetische Aspekte und bekannte genetische CAKUT-Ursachen}

Überwiegend (in etwa $85 \%$ der Fälle) treten CAKUT sporadisch auf. In etwa $15 \%$ der Fälle hingegen wird ein familiäres Auftreten beobachtet, wobei sowohl dominante als auch rezessive Vererbungsmuster vorkommen können [86]. Dabei können CAKUT isoliert auftreten sowie Teil einer milden oder komplexen syndromalen Erkrankung sein, wobei die VACTERL-Assoziation, das MeckelGruber- und das Prune-Belly-Syndrom bei CAKUT-Patienten häufiger vorkommen [81]. Da CAKUT bei mehr als 500 Syndromen auftreten können [51], ist es nicht verwunderlich, dass bei etwa einem Drittel der Neugeborenen mit CAKUT zusätzlich extrarenale Veränderungen beobachtet wurden, darunter Fehlbildungen des Skeletts, Verdauungstrakts, Herzens, Nervensystems und Genitaltrakts [81].

Genetische CAKUT-Ursachen können numerische Veränderungen ganzer Chromosomen sein (bei ca. 6\% der Patienten) [81]. So können CAKUT beispielsweise bei den Trisomien 13, 18, 21, dem Ullrich-Turner-Syndrom und bei Triploidie vorkommen [81]. Mikrodeletionen oder Mikroduplikationen finden sich bei $10-15 \%$ der CAKUT-Patienten [70, 94], wobei die chromosomalen Banden 1q21.1, 16p11.2, 17q12 (HNF1B-Lokus) und 22q11.2 (DiGeorge-SyndromLokus, der das CRKL-Gen einschließt) am häufigsten betroffen sind [70]. Bei weiteren etwa $20 \%$ der CAKUT-Fälle finden sich pathogene Veränderungen einzelner CAKUT-assoziierter Gene [31, 86], wobei bislang etwa 50 Gene bekannt sind, die bei der CAKUT-Pathogenese eine Rolle spielen (•Tab. 1$)$. Davon sind $H N F 1 B$ und PAX2 besonders häufig von Mutationen/Deletionen betroffen, jeweils in ca. $5 \%$ der CAKUT-Fälle [31, 92]. Würden also alle bisher bekannten genetischen Ursachen bei CAKUT-Patienten abgeklärt, so blieben dennoch über die Hälfte der Fälle genetisch ungeklärt.

Die CAKUT-assoziierten Gene kodieren insbesondere für Transkriptionsfaktoren, aber auch für sezernierte Proteine einschließlich Liganden und membranständige Proteine einschließlich Rezeptoren sowie andere Proteine 


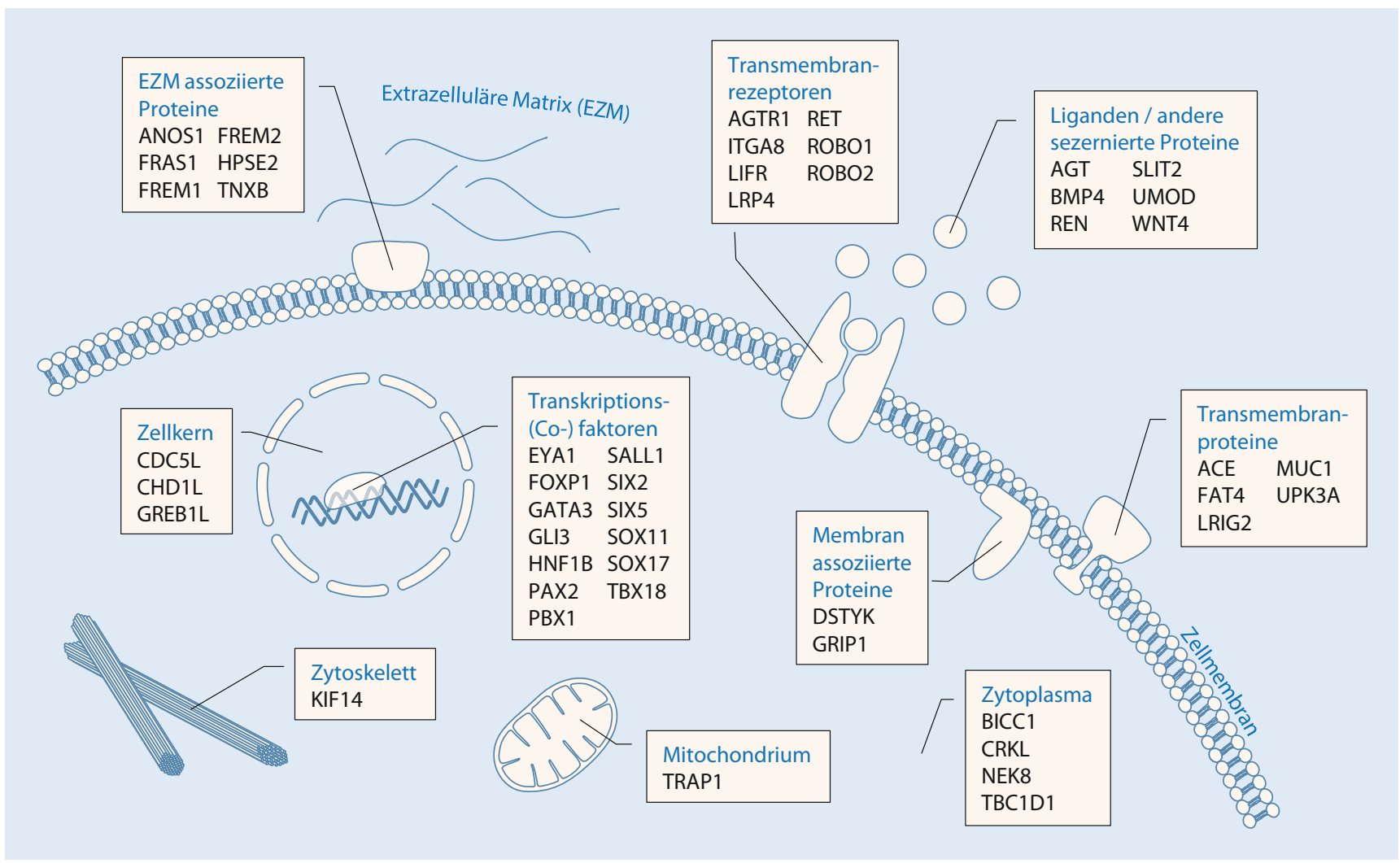

Abb. 3 A Hauptsächlicher zellulärer Wirkort der durch die etwa 50 humanen CAKUT (Congenital Anomalies of the Kidney and Urinary Tract)-Gene kodierten Proteine (Quellen: www.uniprot.org, www.genecards.org und Literatur aus • Tab. 1)

(• Abb. 3), die an unterschiedlichen Signalwegen beteiligt sind. Dabei spielt der über den Liganden GDNF („glial cell derived neurotrophic factor") und die Ko-Rezeptoren RET und GFRA1 („GDNF family receptor alpha $1^{\prime)}$ ) vermittelte Signalweg eine wichtige Rolle bei der Kommunikation zwischen dem metanephrogenen Mesenchym und dem Wolff'schen Gang während der Niereninduktion. Daher verwundert es nicht, dass viele der durch bekannte CAKUTGene, z.B. PAX2 und SALL1, kodierten Proteine „upstream“ oder „downstream“ dieses Signalwegs agieren [73]. Weitere an der Morphogenese der Nieren und an der CAKUT-Pathogenese beteiligte Gene und deren Signalwege sind z.B. BMP4 (BMP-), DSTYK (FGF-) und WNT4 (WNT-,,signaling“) sowie die für die extrazellulären Matrixproteine kodierenden Gene FRAS1, FREM1 und FREM2 [73, 86]. Wir konnten kürzlich zeigen, dass LIFR-Mutationen bzw. LifrDefizienz und damit der Signalweg des zur Interleukin 6-Familie gehörenden Cytokins LIF („LIF, interleukin 6 family cytokine“) mit der Entstehung insbesondere einer obstruktiven Uropathie assoziiert sind [46].

CAKUT ist durch eine ausgeprägte variable Expressivität zwischen Individuen mit der gleichen Mutation (d.h. unterschiedliche Ausprägung der renalen und/oder extrarenalen Phänotypen) und innerhalb eines Individuums (d.h. unterschiedliche Ausprägung links und rechts) sowie durch unvollständige Penetranz gekennzeichnet. Letzteres hat zur Folge, dass es in Familien mit dominantem Erbgang Träger pathogener heterozygoter Mutationen geben kann, die nicht von einem CAKUT-Phänotyp betroffen sind (z.B. [45, 92]). Ein seltenes Beispiel für eine dominante CAKUT-Variante, die in einer Vier-GenerationenFamilie zu vollständiger Penetranz führt, ist eine heterozygote „frameshift“ Mutation im TBX18-Gen [89]. Dieser starke genetische Effekt mag dadurch begründet sein, dass diese TBX18 „frameshift“ Mutation dominant negativ wirkt [89], und Tbx18 die Ureterentwicklung entscheidend reguliert, wie in der Tbx18 „knock- out" Maus gezeigt wurde [3]. Ein weiteres kürzlich beschriebenes CAKUT-Gen, dessen Veränderung zu einem starken genetischen Effekt führt, ist GREB1L $[8,14]$. In einer Drei-Generationen-Familie war sogar eine heterozygote GREB1L „missense“ Mutation mit einem annähernd voll penetranten CAKUT-Phänotyp, einer Nierenagenesie, verbunden [8]. Dies mag mit einem essenziellen Einfluss von GREB1L auf die Niereninduktion, wie durch das Vorkommen einer beidseitigen Nierenagenesie in der Greb1l „knockout ${ }^{\text {“ }}$ Maus gezeigt wurde [14], zusammenhängen. Bei Genen/Varianten mit schwächeren Effekten wird das zusätzliche Vorliegen von (i) weiteren seltenen pathogenen Varianten, z. B. digene Vererbung [45, 74], (ii) häufigen Varianten als „modifier “der CAKUT-Pathogenese, z. B. RET, c.2071G > A; p. (G691S), rs1799939, , minor allele frequency“ (MAF) $=17 \%$ [11] und (iii) epigenetischen oder Umwelteinflüssen [58] als mögliche Gründe für das Vorhandensein bzw. den Schweregrad des CAKUT-Phänotyps diskutiert. 


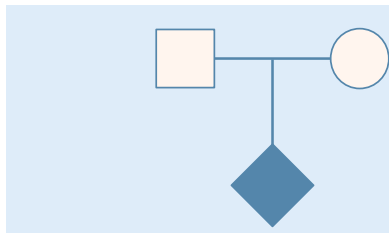

CAKUT tritt in ca. $85 \%$ der Fälle sporadisch auf

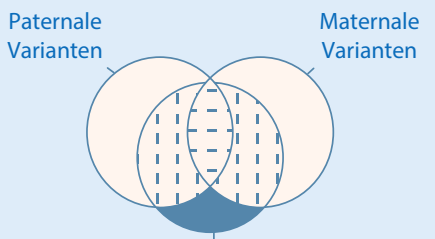

De novo Varianten

Trio-basierte Strategie zur Identifizierung potentiell pathogener de novo Varianten durch Ausschluss der elterlichen Varianten

Abb. $4 \Delta$ Bei sporadischen Patienten mit Phänotypen, die wie CAKUT (Congenital Anomalies of the Kidney and Urinary Tract) meist dominant erblich sind, ist eine Trio-basierte De-novo-Analyse von „whole exome sequencing" Daten Erfolg versprechend und wurde bereits zur Identifizierung neuer CAKUT-Gene genutzt $[45,46]$. Da ein rezessiver Erbgang bei CAKUT auch möglich ist, sollten die bei der Trio-Analyse identifizierten „compound" heterozygoten und homozygoten Varianten des Patienten ebenfalls beachtet werden

\section{Strategien zum Nachweis neuer CAKUT-Gene und deren Erfolge}

Die Identifizierung neuer CAKUT-Gene oder -Genloci erfolgte in den vergangenen Jahrzehnten im Wesentlichen mittels Kandidatengenstrategie (überwiegend wurden wichtige Nierenentwicklungsgene gezielt sequenziert, z. B. $[71,93]$ ), Kopplungsanalyse (z. B. [67]) oder genomischer Mikroarrayanalyse (z. B. [7, 48, 94]). Nach Einführung von „next generation sequencing“ Technologien konnten durch Panelsequenzierungen zunächst Dutzende, dann Hunderte humane und murine CAKUT-(Kandidaten)Gene gleichzeitig in größeren Patientenkohorten untersucht werden. Obwohl die Aufklärungsrate mit der Anzahl untersuchter Gene sowie dem Schweregrad des Phänotyps anstieg (17 Gene bei Patienten mit nicht syndromalen CAKUT: Aufklärungsrate $6 \%$ [35] versus 330 Gene bei CAKUTPatienten, die zu $45 \%$ schwerwiegende fetale Fälle waren: Aufklärungsrate 18\%
[31]), zeigte sich hier die große genetische Heterogenität von CAKUT, die eine Identifizierung kausativer Varianten mit einem begrenzten Genpanel erschwert [59].

Getrieben durch diese Erkenntnis und durch die Technologie, wurden die nächsten CAKUT-Familien mittels Gesamtexomsequenzierung (,whole exome sequencing", WES) untersucht. Dabei wurden beispielsweise folgende Strategien bei der Datenanalyse angewandt:

1. Kopplungsstrategie: Durch WES an drei entfernt verwandten Betroffenen einer großen Vier-GenerationenFamilie mit dominant vererbten CAKUT gelang die Identifizierung der kausativen heterozygoten Variante in einem neuen humanen CAKUT-Gen (TBX18) [89],

2. Zwei-Hit- und Homozygotiestrategie: WES an mehreren betroffenen Kindern aus teilweise konsanguinen Familien, bei denen ein rezessiver Erbgang vermutet wurde, ergab biallelische (bei der konsanguinen Familie homozygote) Varianten im neuen humanen CAKUT-Gen ITGA8 [34],

3. Überlappungsstrategie: WES an einer Kohorte von 183 nicht verwandten CAKUT-Patienten mit ähnlichem Phänotyp ergab häufige Mutationen im neuen CAKUT-Gen GREB1L [14],

4. De-novo-Strategie: Um die epidemiologisch relevanten sporadischen CAKUT-Patienten abzuklären, wandten wir diese bei dominant erblichen Phänotypen Erfolg versprechende Strategie an und identifizierten die neuen CAKUT-Gene TBC1D1 und LIFR [45, 46]. Bei der Trio-basierten De-novo-Analyse der WES-Daten des Patienten und seiner gesunden Eltern werden potenziell pathogene De-novo-Varianten des Patienten durch Ausschluss der elterlichen Varianten identifiziert (• Abb. 4).

Wie schon bei der Panelsequenzierung zeigt sich auch bei der exomweiten Analyse, dass die Wahrscheinlichkeit des Nachweises einer genetischen CAKUT-Ursache bei schwer Betroffenen, die intrauterin versterben (dann steht $u$. U. fetales
Material zur Verfügung) oder bereits in der ersten Lebensdekade ein terminales Nierenversagen entwickeln, höher ist als bei leichter, z. B. einseitig, Betroffenen. Auch die Untersuchung großer Familien mit vielen CAKUT-Patienten ist häufig erfolgreich $[8,89]$. Würde man sich bei der Suche nach neuen CAKUT-Genen jedoch auf die Untersuchung von Familien mit mehreren CAKUT-Patienten beschränken, so könnten Varianten, die die Fertilität stark beeinträchtigen, unentdeckt blieben. Da ein Zusammenhang zwischen der Entwicklung von Nieren und Harntrakt und des Genitalsystems besteht, können CAKUT-Gene, z. B. LIFR [46] und GREB1L [14], auch mit Fehlbildungen des Genitaltrakts assoziiert sein und damit einen Einfluss auf die Fertilität der Patienten haben. Auch unter diesem Gesichtspunkt sollte die $\mathrm{Su}$ che nach neuen kausativen Varianten bei sporadischen CAKUT nicht vernachlässigt werden.

\section{Tiermodelle und CAKUT}

Bei der Erforschung der Nierenentwicklung ist die Maus (Mus musculus) schon aufgrund ihrer phylogenetischen Nähe zum Menschen das hauptsächliche Tiermodell. Durch die Untersuchung von Mausmodellen konnten bisher über 180 monogene CAKUT-Ursachen beschrieben werden [86]. Auch bei der Suche nach neuen genetischen Ursachen von humanen CAKUT sind diese Gene vielversprechende Kandidaten. Tatsächlich wurde bei einer Reihe von Genen, z. B. $P B X 1$ und TBX18, eine Beteiligung an der murinen CAKUT-Pathogenese beschrieben [3, 76], Jahre bevor Varianten in diesen Genen als kausativ für humane CAKUT nachgewiesen wurden [31, 89]. Auch viele Signalwege, die bei der CAKUT-Pathogenese eine Rolle spielen, wurden zunächst im Mausmodell identifiziert und genau charakterisiert, z. B. die GDNF-RET-GFRA1- oder BMPSignalwege [73]. Andersherum dienen heute Mausmodelle zur Validierung und Charakterisierung von „next generation sequencing" basierten Befunden an CAKUT-Patienten. So trug z. B. die Möglichkeit, auch subtilere Phänotypen wie Veränderungen der Ureterhistologie 


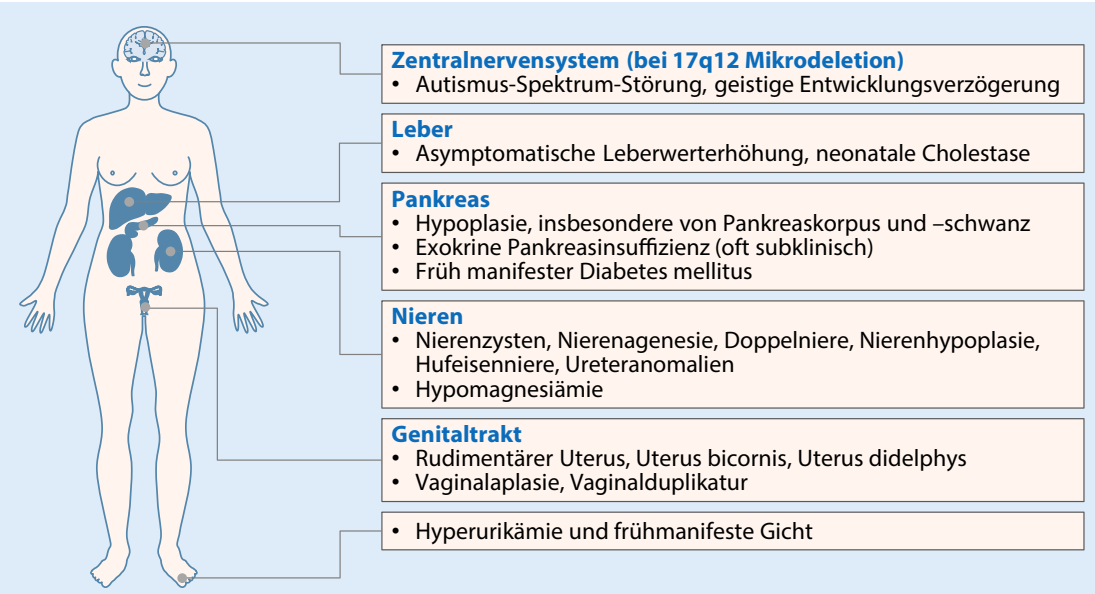

a Renale Zysten und Diabetes-Syndrom

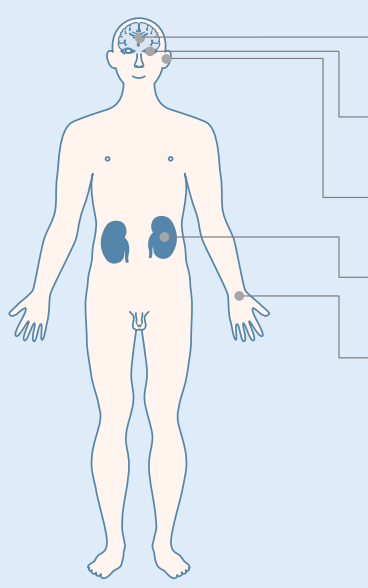

b Renales-Kolobom-Syndrom

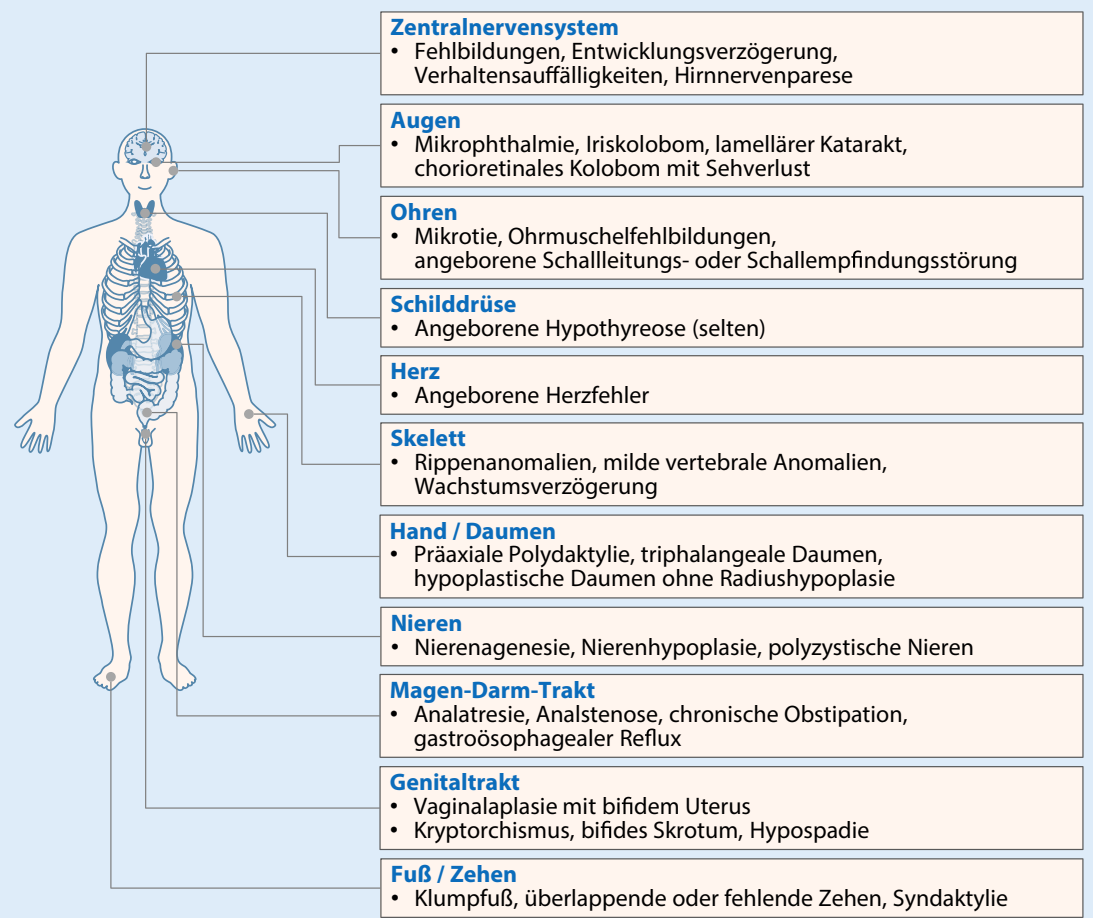

cTownes-Brocks-Syndrom
Zentralnervensystem

- Fehlbildungen, Entwicklungsverzögerung (sehr selten)

Augen

- Sehnervkolobom, Netzhautkolobom, Sklera-Staphylom,

Sehnervzyste, Mikrophthalmie, Iriskolobom, Myopie, Nystagmus

Ohren

- Hochton-Schwerhörigkeit

Nieren

- Nierenhypodysplasie, multizystisch-dysplastische Nieren,

Oligomeganephronie, Hufeisenniere, vesikoureteraler Reflux

Gelenke

- Überdehnbarkeit der Gelenke

- Klumpfuß, überlappende oder fehlende Zehen, Syndaktylie

Augen

- Mikrophthalmie, Iriskolobom, lamellärer Katarakt,

Ohren

Mikrotie, Ohrmuschelfehlbildungen

Rippenanomalien, milde vertebrale Anomalien,

Wachstumsverzögerung

- Prol Daumen

- Nierenagenesie, Nierenhypoplasie, polyzystische Nieren

Magen-Darm-Trakt

- Kryptorchismus, bifides Skrotum, Hypospadie

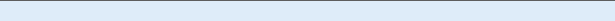

in der Maus ausführlich zu untersuchen, dazu bei, das durch WES bei CAKUTPatienten identifizierte Kandidatengen LIFR als CAKUT-Gen zu etablieren [46]. Neue Technologien wie CRISPR/Cas9 "genomic engineering" ermöglichen es, mit vertretbarem Aufwand bei CAKUTPatienten nachgewiesene Varianten, insbesondere spezifische "missense“ Varianten, im Mausmodell zu modellieren und ein Auftreten des humanen Phänotyps, z.B. eine Nierenagenesie, zu überprüfen [8].

Beim Krallenfrosch (Xenopus laevis) bietet sich die Möglichkeit, die embryonale Niere (Pronephros) auf einer Seite des Tieres zu manipulieren und deren Entwicklung im Vergleich zur nicht manipulierten Seite direkt durch die transparente Haut $\mathrm{zu}$ beobachten. So wurde ein „knockdown“ humaner CAKUTGene wie HNF1B, PAX2 und WNT4 im Xenopusmodell durchgeführt, um deren Einfluss auf die Pronephrosentwicklung $\mathrm{zu}$ untersuchen [50]. Wenn nach dem „knockdown“, z. B. von nrip1, ein „rescue“ der Pronephrosentwicklung durch eine humane NRIP1-Variante, die mit dem Phänotyp in einer CAKUT-Familie kosegregiert, nicht möglich ist, spricht dies für die Pathogenität der humanen Variante [90]. Auch der Zebrafisch ( $\mathrm{Da}$ nio rerio) eignet sich dafür, die Konsequenz humaner Varianten zu analysieren. So konnte durch einen RNA-Injektionsassay gezeigt werden, dass humane SIX2- und BMP4-Varianten zu einer Beeinträchtigung der Zebrafischentwicklung führen [93].

Bei Kandidatengenen, deren „knockout/knockdown" im Tiermodell einen schweren CAKUT-Phänotyp hervorruft, ist es nicht unwahrscheinlich, dass deren Varianten beim Menschen zu intrauteri-

Abb. $5<$ Schematische Darstellung des renalen und extrarenalen Anomaliespektrums von Syndromen, die häufig mit CAKUT (Congenital Anomalies of the Kidney and Urinary Tract) assoziiert sind. Phänotypen des a Renale Zysten und Diabetes-Syndroms, verursacht durch HNF1B-Mutationen/Deletionen [12], b Renales-Kolobom-Syndroms, verursacht durch PAX2-Mutationen [75] sowie c Townes-BrocksSyndroms, verursacht durch SALL1-Mutationen [43] 


\section{Infobox \\ Weiterführende Informationen}

Zentrum für angeborene Nierenerkrankungen am Zentrum für seltene Erkrankungen (ZSE) der Medizinischen Hochschule Hannover, https://www.mh-hannover.de/30269.html Gesellschaft für Pädiatrische Nephrologie (GPN), https://gpn.de

ner Letalität führen können. Dann wären pathogene Varianten in solchen Genen bei lebenden CAKUT-Patienten selten, und solche Gene wären für CAKUT bei Kindern und Erwachsenen wenig relevant. Andersherum ist zu erwarten, dass wenn Varianten lebender CAKUTPatienten im Tiermodell modelliert werden, der resultierende Phänotyp subtil sein kann und eine gründliche Charakterisierung erfordert.

\section{Translationale Relevanz der CAKUT-Genetik: Fallbeispiele}

Während das empirische Wiederholungsrisiko z.B. für Nierenagenesie für Geschwister mit 3,5\% bei nicht betroffenen Eltern beziffert wird, und mit $20 \%$, wenn ein Elternteil auch betroffen ist [60], ermöglicht die Aufklärung der genetischen CAKUT-Ursache die Präzisierung dieses Wiederholungsrisikos und ist daher für die genetische Beratung von großem Nutzen. Für die klinische Versorgung des renalen Phänotyps hingegen ist derzeit ein Nachweis der zugrunde liegenden genetischen Veränderung in der Regel nicht erforderlich. Jedoch kann der Patient erheblich davon profitieren, dass die genetische Diagnostik auf mögliche assoziierte extrarenale Manifestationen hinweist, die dann gezielt abgeklärt werden können und deren Auftreten möglicherweise verhindert oder hinausgezögert werden kann. Das vielleicht eindrücklichste Beispiel ist das erhöhte Risiko für Diabetes im Jugend- und jungen Erwachsenenalter (MODY-Syndrom Typ 5) bei CAKUT-Patienten mit heterozygoten Varianten oder Mikrodeletionen, die das $H N F 1 B$-Gen betreffen (- Abb. 5a; [12]). Bei solchen Patienten ist eine frühzeitige Diagnose des Diabetes entscheidend, um Spätschäden zu reduzieren. Auch in anderen Fällen kann eine genetische Abklärung wichtig sein, wie zwei unserer eigenen Patienten belegen.

Fallbeispiel 1. Bei einem Patienten mit sporadischer beidseitiger Nierendysplasie, der im Alter von 5 Jahren eine Nierentransplantation benötigte, stand der renale Phänotyp im Vordergrund, sodass eine isolierte CAKUT vermutet wurde. WES ergab eine heterozygote $P A X 2$ „frameshift" Variante, die bei Patienten mit Renales-Kolobom-Syndrom (RCS) bereits beschrieben war [75] und laut Segregationsanalyse mittels SangerSequenzierung bei unserem CAKUTPatienten de novo vorlag. Daher konnte bei unserem Patienten ein RCS, das neben CAKUT häufig mit Augenanomalien (u.a. Sehnerv-, Netzhaut- und Iriskolobomen, Myopie unterschiedlicher Ausprägung) und selten mit Hörstörungen assoziiert ist (• Abb. 5b; [75]), diagnostiziert werden. Augen- und HNOärztliche Untersuchungen ergaben eine ausgeprägte Myopie beim Patienten, die frühzeitig korrigiert werden konnte. Aufgrund des Nachweises einer De-novo-Variante ist das Wiederholungsrisiko für weitere Nachkommen der gesunden Eltern nur geringfügig erhöht, während das Risiko für die Nachkommen des Betroffenen bei $50 \%$ liegt, von einem RCS betroffen zu sein, da die nachgewiesene PAX2-Mutation hoch penetrant ist.

Fallbeispiel 2. Ein Patient mit sporadischer beidseitiger Nierendysplasie und ausgeprägtem Kleinwuchs benötigte im zweiten Lebensjahr eine Nierentransplantation. WES, gefolgt von Sanger-Sequenzierung, ergaben beim Patienten eine unbeschriebene heterozygote de novo SALL1 „nonsense“ Variante. Pathogene Varianten in SALL1 liegen dem TownesBrocks-Syndrom (TBS) zugrunde, dessen Merkmale neben CAKUT (42\%), Hand/Daumen- (89\%), Ohr- (87\%) sowie Analanomalien (84\%) sind, die gemeinsam mit Herzfehlern (12-50\%), Wachstumsstörungen (6-29\%) und diversen weiteren Fehlbildungen auftreten können (• Abb. 5c; [44]). Obwohl die hier identifizierte Variante noch nicht beschrieben wurde, konnten wir diese nach den ACMG Guidelines [63] eindeutig als pathogen einstufen. Damit ist die vorher nicht vermutete Diagnose TBS beim Patienten als sehr wahrscheinlich bis gesichert anzusehen mit der klinischen Konsequenz einer intensivierten Diagnostik extrarenaler Fehlbildungen einschließlich eines Hörtests und einer Echokardiographie. Das Vorliegen eines TBS würde auch erklären, warum der Patient trotz optimaler nephrologischer Behandlung einen ausgeprägten Kleinwuchs aufwies. Da sich bei über der Hälfte der TBS-Patienten die anfänglich milden Hörstörungen mit dem Alter verstärken können [44], sollte auch bei erwachsenen Patienten an regelmäßige $\mathrm{HNO}$-ärztliche Kontrollen gedacht werden. Auch hier ist das Wiederholungsrisiko für die gesunden Eltern nur geringfügig erhöht, während $50 \%$ der Nachkommen des Patienten dessen heterozygote SALL1Variante, wahrscheinlich verbunden mit TBS-Merkmalen, aufweisen würden.

\section{Fazit für die Praxis}

- Da Fehlbildungen aus dem CAKUTSpektrum insgesamt recht häufig sind und mindestens die Hälfte der Fälle mit chronischer Niereninsuffizienz im Kindes- und Jugendalter verursachen, sind CAKUT ein epidemiologisch hoch relevantes Thema.

- Diagnostisch stehen radiologische, insbesondere sonographische Verfahren im Vordergrund.

- CAKUT sind genetisch sehr heterogen. Bei syndromalen CAKUT können verschiedene numerische oder strukturelle Chromosomenstörungen, einschließlich Mikrodeletionen und Mikroduplikationen insbesondere der chromosomalen Bande 17q12, ursächlich sein. Bei nicht oder geringgradig syndromalen CAKUT finden sich eher Mutationen in den ca. 50 bisher bekannten humanen CAKUTGenen, besonders häufig in HNF1B und $P A X 2$, die insgesamt allerdings nur ca. 20\% der CAKUT-Fälle erklären. Daher spielen bei CAKUT sowohl die Abklärung von Kopienzahlveränderungen, derzeit z. B. mittels Array-basierter komparativer genomischer Hybridisierung, als auch die gezielte Sequenzanalyse CAKUTassoziierter Gene oder das Screening 
des gesamten Exoms eine Rolle. Bei sporadischen Patienten ist WES der Patienten-Eltern-Trios und eine Triobasierte Analyse im Hinblick auf de novo und biallelische Varianten eine vielversprechende Vorgehensweise. Bei dominantem Erbgang können variable Expressivität und inkomplette Penetranz die Interpretation der genetischen Befunde erschweren.

- Gelingt eine Abklärung der genetischen CAKUT-Ursache, so können Wiederholungsrisiken präzisiert werden und gezielte Untersuchungen im Hinblick auf extrarenale Phänotypen erfolgen.

\section{Korrespondenzadresse}

Prof. Dr. med. Ruthild G. Weber

Institut für Humangenetik, Medizinische Hochschule Hannover

Carl-Neuberg-Straße 1, 30625 Hannover, Deutschland

Weber.Ruthild@mh-hannover.de

Förderung. Diese Arbeit wurde durch die Else Kröner-Fresenius-Stiftung (2014_A234) und die Deutsche Forschungsgemeinschaft (KO 5614/2-1) gefördert.

\section{Einhaltung ethischer Richtlinien}

Interessenkonflikt. A. Kosfeld, H. Martens, I. Hennies, D. Haffner und R.G. Weber geben an, dass kein Interessenkonflikt besteht.

Die vorgestellten Fallbeispiele sind Teil einer Studie, die im Einklang mit der Deklaration von Helsinki in ihrer aktuellen Fassung von 2013 erfolgte. Die Eltern haben für sich und ihre Kinder schriftlich in die Teilnahme eingewilligt.

Open Access. Dieser Artikel wird unter der Creative Commons Namensnennung 4.0 International Lizenz (http://creativecommons.org/licenses/by/4.0/deed. de) veröffentlicht, welche die Nutzung, Vervielfältigung, Bearbeitung, Verbreitung und Wiedergabe in jeglichem Medium und Format erlaubt, sofern Sie den/die ursprünglichen Autor(en) und die Quelle ordnungsgemäßnennen, einen Link zur Creative Commons Lizenz beifügen und angeben, ob Änderungen vorgenommen wurden.

\section{Literatur}

1. Abdelhak S, Kalatzis V, Heilig R et al (1997) Clustering of mutations responsible for branchiooto-renal (BOR) syndrome in the eyes absent homologous region (eyaHR) of EYA1. Hum Mol Genet 6:2247-2255
2. Afzal M,Zaman Q, KornakU etal (2017) Novel splice mutation in LRP4 causes severe type of CenaniLenz syndactyly syndrome with oro-facial and skeletal symptoms. Eur J Med Genet 60:421-425

3. Airik R, Bussen M, Singh MK et al (2006) Tbx18 regulates the development of the ureteral mesenchyme. JClin Invest 116:663-674

4. Alazami AM, Shaheen R, Alzahrani F et al (2009) FREM1 mutations cause bifid nose, renal agenesis, and anorectal malformations syndrome. Am JHum Genet 85:414-418

5. Bekheirnia MR, Bekheirnia N, Bainbridge MN et al (2017) Whole-exome sequencing in the molecular diagnosis of individuals with congenital anomalies of the kidney and urinary tract and identification of a new causative gene. Genet Med 19:412-420

6. Bertoli-Avella AM, Conte ML, Punzo F et al (2008) $\mathrm{ROBO} 2$ gene variants are associated with familial vesicoureteral reflux. J Am Soc Nephrol 19:825-831

7. Brockschmidt A, Chung B, Weber S et al (2012) CHD1L: a new candidate gene for congenital anomalies of the kidneys and urinary tract (CAKUT). Nephrol Dial Transplant 27:2355-2364

8. Brophy PD, Rasmussen M, Parida M (2017) A gene implicated in activation of retinoic acid receptor targets is a novel renal agenesis gene in humans. Genetics 207:215-228

9. Caiulo VA, Caiulo S, Gargasole C et al (2012) Ultrasound mass screening for congenital anomalies of the kidney and urinary tract. Pediatr Nephrol 27:949-953

10. Cascio S, Paran S, Puri P (1999) Associated urological anomalies in children with unilateral renal agenesis. JUrol 162:1081-1083

11. Chatterjee R, Ramos E, Hoffman M et al (2012) Traditional and targeted exome sequencing reveals common, rare and novel functional deleterious variants in RET signaling complex in a cohort of living US patients with urinary tract malformations. Hum Genet 131:1725-1738

12. Clissold RL, Hamilton AJ, Hattersley AT et al (2015) HNF1B-associated renal and extra-renal diseasean expanding clinical spectrum. Nat Rev Nephrol 11:102-112

13. Daly SB, Urquhart JE, Hilton Eet al (2010) Mutations in HPSE2 cause urofacial syndrome. Am J Hum Genet 86:963-969

14. De Tomasi L, David P, Humbert $C$ et al (2017) Mutations in GREB1L cause bilateral kidney agenesis in humans and mice. Am J Hum Genet 101:803-814

15. Elahi S, Homstad A, Vaidya $\mathrm{H}$ et al (2016) Rare variants in tenascin genes in a cohort of children with primary vesicoureteric reflux. Pediatr Nephrol 31:247-253

16. Filges I, Nosova E, Bruder E et al (2014) Exome sequencing identifies mutations in as a novel cause of an autosomal recessive lethal fetal ciliopathy phenotype. Clin Genet 86:220-228

17. Firth HV, Hurst JA (2005) Oxford desk reference clinical genetics. Oxford University Press, Oxford

18. Frank V, Habbig S, Bartram MP et al (2013) Mutations in NEK8 link multiple organ dysplasia with altered Hippo signalling and increased c-MYC expression. Hum Mol Genet 22:2177-2185

19. Gbadegesin RA, Brophy PD, Adeyemo A et al (2013) TNXB Mutations Can Cause Vesicoureteral Reflux.J Am Soc Nephrol 24:1313-1322

20. Gimelli S, Caridi G, Beri S et al (2010) Mutations in SOX17 are associated with congenital anomalies of the kidney and the urinary tract. Hum Mutat 31:1352-1359

21. Grampa V, Delous M, Zaidan M et al (2016) Novel NEK8 mutations cause severe syndromic renal cystic dysplasia through YAP dysregulation. PLoS Genet 12:e1005894

22. Gribouval O, Gonzales M, Neuhaus T et al (2005) Mutations in genes in the renin-angiotensin system are associated with autosomal recessive renal tubular dysgenesis. Nat Genet 37:964-968

23. Gribouval $O$, Morinière $V$, Pawtowski A et al (2012) Spectrum of mutations in the renin-angiotensin system genes in autosomal recessive renal tubular dysgenesis. Hum Mutat 33:316-326

24. Groenen PMA, Vanderlinden $G$, Devriendt $K$ et al (1998) Rearrangement of the human CDC5L gene by a $(6 ; 19)(p 21 ; q 13.1)$ in a patient with multicystic renal dysplasia. Genomics 49:218-229

25. Groothoff JW, Offringa M, Grootenhuis M et al (2018) Long-term consequences of renal insufficiency in children: lessons learned from the Dutch LERIC study. Nephrol Dial Transplant 33:552-560

26. HaffnerD, Gröne HJ,ZappelHF (2013) Nephrologie. In: Speer CP, Gahr M (Hrsg) Pädiatrie. Springer, Berlin, S679-706

27. Harambat J, van Stralen KJ, Kim JJ et al (2012) Epidemiology of chronickidney disease in children. Pediatr Nephrol 27:363-373

28. Hardelin JP, Levilliers J, del Castillo I et al (1992) $X$ chromosome-linked Kallmann syndrome: stop mutations validate the candidate gene. Proc Natl Acad SciU SA 89:8190-8194

29. Hart TC, Gorry MC, Hart PS et al (2002) Mutations of the UMOD gene are responsible for medullary cystic kidney disease 2 and familial juvenile hyperuricaemic nephropathy. JMed Genet 39:882892

30. Heidet L, Decramer S, Pawtowski A et al (2010) Spectrum of HNF1B mutations in a large cohort of patients who harbor renal diseases. Clin J Am Soc Nephrol 5:1079-1090

31. Heidet L, Morinière V, Henry C et al (2017) Targeted exome sequencing identifies PBX1 as involved in monogenic congenital anomalies of the kidney and urinary tract. J Am Soc Nephrol 28:2901-2914

32. Horikawa Y, Iwasaki N, Hara Met al (1997) Mutation in hepatocyte nuclear factor-1 beta gene (TCF2) associated with MODY. Nat Genet 17:384-385

33. Hoskins BE, Cramer CH, Silvius D et al (2007) Transcription factor SIX5 is mutated in patients with branchio-oto-renal syndrome. Am J Hum Genet 80:800-804

34. Humbert C, Silbermann F, Morar B et al (2014) Integrin alpha 8 recessive mutations are responsible for bilateral renal agenesis in humans. Am J Hum Genet 94:288-294

35. Hwang DY, Dworschak GC, Kohl S et al (2014) Mutations in 12 known dominant disease-causing genes clarify many congenital anomalies of the kidney and urinary tract. Kidney Int 85:1429-1433

36. Hwang DY, Kohl S, Fan X et al (2015) Mutations of the SLIT2-ROBO2 pathway genes SLIT2 and SRGAP1 confer risk for congenital anomalies of the kidney and urinary tract. Hum Genet 134:905-916

37. Jadeja S, Smyth I, Pitera JE etal (2005) Identification of a new gene mutated in Fraser syndrome and mouse myelencephalic blebs. Nat Genet 37:520525

38. Jenkins D, Bitner-Glindzicz M, Malcolm S et al (2005) De novo Uroplakin Illa heterozygous mutations cause human renal adysplasia leading to severe kidney failure. J Am Soc Nephrol 16:2141 2149

39. Johnston JJ, Olivos-Glander I, Killoran C et al (2005) Molecular and clinical analyses of Greig cephalopolysyndactyly and Pallister-Hall syndromes: robust phenotype prediction from the 
type and position of GLI3 mutations. Am J Hum Genet 76:609-622

40. Khan TN, Klar J, Ali Z et al (2013) Cenani-Lenz syndrome restricted to limb and kidney anomalies associated with a novel LRP4 missense mutation. Eur J Med Genet 56:371-374

41. Kirby A, Gnirke A, Jaffe DB et al (2013) Mutations causing medullary cystic kidney disease type 1 lie in a large VNTR in MUC1 missed by massively parallel sequencing. Nat Genet 45:299-303

42. Kohl S, Hwang DY, Dworschak GC et al (2014) Mild recessive mutations in six Fraser syndromerelated genes cause isolated congenital anomalies of the kidney and urinary tract. J Am Soc Nephrol 25:1917-1922

43. Kohlhase J, Wischermann A, Reichenbach $H$ et al (1998) Mutations in the SALL1 putative transcription factor gene cause Townes-Brocks syndrome. Nat Genet 18:81-83

44. Kohlhase J (2007) Townes-Brocks syndrome. In: Adam MP, Ardinger HH, Pagon RA et al (Hrsg) GeneReviews. University of Washington, Seattle, 1993-2018

45. Kosfeld A, Kreuzer M, Daniel C et al (2016) Wholeexome sequencing identifies mutations of TBC1D1 encoding a Rab-GTPase-activating protein in patients with congenital anomalies of the kidneys and urinary tract (CAKUT). Hum Genet 135:69-87

46. Kosfeld A, Brand F, Weiss AC et al (2017) Mutations in the leukemia inhibitory factor receptor (LIFR) gene and Lifr deficiency cause urinary tract malformations. Hum Mol Genet 26:1716-1731

47. Kraus MR, Clauin S, Pfister Y et al (2012) Two mutations in human BICC1 resulting in Wnt pathway hyperactivity associated with cystic renal dysplasia. Hum Mutat 33:86-90

48. Le Tanno P, Breton J, Bidart M et al (2017) PBX1 haploinsufficiency leads to syndromic congenital anomalies of the kidney and urinary tract (CAKUT) in humans. J Med Genet 54:502-510

49. Lei TY, Fu F, Li R et al (2017) Whole-exome sequencing for prenatal diagnosis of fetuses with congenital anomalies of the kidney and urinary tract. Nephrol Dial Transplant 32:1665-1675

50. Lienkamp SS (2016) Using Xenopus to study genetic kidney diseases. Semin Cell Dev Biol 51:117-124

51. Limwongse $C$ (2009) Syndromes and malformations of the urinary tract. In: Avner ED, Harman WE, Niaudet $P$ et al (Hrsg) Pediatric nephrology. Springer, Berlin, S121-156

52. Lopez-Rivera E, Liu YP, Verbitsky M et al (2017) Genetic drivers of kidney defects in the DiGeorge syndrome. N Engl J Med 376:742-754

53. Lu W, van Eerde AM, Fan X et al (2007) Disruption of $\mathrm{ROBO} 2$ is associated with urinary tract anomalies and confers risk of vesicoureteral reflux. Am J Hum Genet 80:616-632

54. Mandel H, Shemer R, Borochowitz ZU et al (2008) SERKAL syndrome: an autosomal-recessive disorder caused by a loss-of-function mutation in WNT4. Am J Hum Genet 82:39-47

55. McGregor L, Makela V, Darling SM (2003) Fraser syndrome and mouse blebbed phenotype caused by mutations in FRAS1/Fras1 encoding a putative extracellular matrix protein. Nat Genet 34:203-208

56. NegrisoloS, BenettiE, CentiSetal (2011)PAX2 gene mutations in pediatric and young adult transplant recipients: kidney and urinary tract malformations without ocular anomalies. Clin Genet 80:581-585

57. Neirijnck Y, Reginensi A, Renkema KY et al (2018) Sox 11 gene disruption causes congenital anomalies of the kidney and urinary tract (CAKUT). Kidney Int 93:1142-1153
58. Nicolaou N, Renkema KY, Bongers EM (2015) Genetic, environmental, and epigenetic factors involved in CAKUT. Nat Rev Nephrol 11:720-731

59. Nicolaou N, Pulit SL, Nijman IJ et al (2016) Prioritization and burden analysis of rare variants in 208 candidate genes suggest they do not play a major role in CAKUT. Kidney Int 89:476-486

60. Pohl M, Bhatnagar V, Mendoza SA et al (2002) Toward an etiological classification of developmental disorders of the kidney and upper urinary tract. Kidney Int 61:10-19

61. Queisser-Luft A, Stolz G, Wiesel A et al (2002) Malformations in newborn: results based on 30,940 infants and fetuses from the Mainz congenital birth defect monitoring system (1990-1998). Arch GynecolObstet 266:163-167

62. Rasmussen M, Sunde L, Nielsen ML et al (2018) Targeted gene sequencing and whole-exome sequencing in autopsied fetuses with prenatally diagnosed kidney anomalies. Clin Genet 93:860869

63. Richards S, Aziz N, Bale S et al (2015) Standards and guidelines for the interpretation of sequence variants: a joint consensus recommendation of the American College of Medical Genetics and Genomics and the Association for Molecular Pathology. Genet Med 17:405-424

64. Riedhammer KM, Siegel C, Alhaddad B et al (2017) Identification of a novel heterozygous de novo 7-bp frameshift deletion in PBX1 by whole-exome sequencing causing a multi-organ syndrome including bilateral dysplastic kidneys and hypoplastic clavicles. Front Pediatr 5:251

65. Saisawat $P$, Tasic V, Vega-Warner V et al (2012) Identification of two novel CAKUT-causing genes by massively parallel exon resequencing of candidate genes in patients with unilateral renal agenesis. Kidney Int 81:196-200

66. Saisawat P, Kohl S, Hilger AC et al (2014) Wholeexome resequencing reveals recessive mutations in TRAP1 in individuals with CAKUT and VACTERL association. Kidney Int 85:1310-1317

67. Sanna-Cherchi S, Caridi G, Wenig PL et al (2007) Localization of a gene for nonsyndromic renal hypodysplasia to chromosome 1p32-33. Am J Hum Genet 80:539-549

68. Sanna-Cherchi S, Sampogna RV, Papeta N et al (2013) Mutations in DSTYK and dominant urinary tract malformations. N Engl J Med 369:621-629

69. Sanna-Cherchi S, Khan K, Westland R (2017) Exome-wide association study identifies GREB1L mutations in congenital kidney malformations. Am JHum Genet 101:789-802

70. Sanna-Cherchi S, Westland R, Ghiggeri GM et al (2018) Genetic basis of human congenital anomalies of the kidney and urinary tract. J Clin Invest 128:4-15

71. Sanyanusin $P$, Schimmenti LA, McNoe LA et al (1995) Mutation of the PAX2 gene in a family with optic nerve colobomas, renal anomalies and vesicoureteral reflux. Nat Genet 9:358-364

72. Schärer K (2002) Nierenhypoplasie und-dysplasie. In: Schärer K, Mehls $\mathrm{O}$ (Hrsg) Pädiatrische Nephrologie. Springer, Berlin, S 149-153

73. Schedl A (2007) Renal anomalies and their developmental origin. Nat Rev Genet 8:791-802

74. Schild R, Knüppel T, Konrad M et al (2013) Double homozygous missense mutations in DACH1 and BMP4 in a patient with bilateral cystic renal dysplasia. Nephrol Dial Transplant 28:227-232

75. Schimmenti LA (2011) Renal coloboma syndrome. Eur JHum Genet 19:1207-1212

76. Schnabel CA, Godin RE, Cleary ML (2003) Pbx1 regulates nephrogenesis and ureteric branching in the developing kidney. Dev Biol 254:262-276
77. Schönfelder EM, Knüppel T, Tasic V et al (2006) Mutations in Uroplakin IIIA are a rare cause of renal hypodysplasia in humans. Am J Kidney Dis 47:1004-1012

78. Skinner MA, Safford SD, Reeves JG et al (2008) Renal aplasia in humans is associated with RET mutations. Am JHum Genet 82:344-351

79. Stals KL, Wakeling M, Baptista J et al (2018) Diagnosis of lethal or prenatal-onset autosomal recessive disorders by parental exome sequencing. Prenat Diagn 38:33-43

80. Stein R, Beetz R, Thüroff JW (2012) Kinderurologie in Klinikund Praxis. Thieme, Stuttgart

81. Stoll C, Dott B, Alembik Y et al (2014) Associated nonurinary congenital anomalies among infants with congenital anomalies of kidney and urinary tract (CAKUT). Eur J Med Genet 57:322-328

82. Stuart HM, Roberts NA, Burgu B et al (2013) LRIG2 mutations cause urofacial syndrome. Am J Hum Genet 92:259-264

83. Tabatabaeifar $M$, Schlingmann KP, Litwin $M$ et al (2009) Functional analysis of BMP4 mutations identified in pediatric CAKUT patients. Pediatr Nephrol 24:2361-2368

84. Ulinski T, Lescure S, Beaufils S et al (2006) Renal phenotypes related to hepatocyte nuclear factor1beta (TCF2) mutations in a pediatric cohort. J Am Soc Nephrol 17:497-503

85. Van der Ven AT, Shril S, Ityel H (2017) Whole-exome sequencing reveals FAT4 mutations in a clinically unrecognizable patient with syndromic CAKUT: a case report. Mol Syndromol 8:272-277

86. Van der Ven AT, Vivante A, Hildebrandt F (2018) Novel insights into the pathogenesis ofmonogenic congenital anomalies of the kidney and urinary tract. J Am Soc Nephrol 29:36-50

87. Van Esch H, Groenen P, NesbitMA etal (2000) GATA3 haplo-insufficiency causes human HDR syndrome. Nature 406:419-422

88. Vivante A, Mark-Danieli $M$, Davidovits $M$ et al (2013) Renal hypodysplasia associates with a WNT4 variant that causes aberrant canonical WNT signaling. J Am Soc Nephrol 24:550-558

89. Vivante A, Kleppa MJ, Schulz J et al (2015) Mutations in TBX18 cause dominant urinary tract malformations via transcriptional dysregulation of ureter development. Am J Hum Genet 97:291-301

90. Vivante A, Mann N, Yonath H et al (2017) A dominant mutation in nuclear receptor interacting protein 1 causes urinary tract malformations via dysregulation of retinoic acid signaling. J Am Soc Nephrol 28:2364-2376

91. Vivante A, Hwang DY, Kohl S et al (2017) Exome sequencing discerns syndromes in patients from consanguineous families with congenital anomalies of the kidneys and urinary tract. J Am Soc Nephrol 28:69-75

92. Weber $S$, Morinière $V$, Knüppel T et al (2006) Prevalence of mutations in renal developmental genes in children with renal hypodysplasia: results of the ESCAPE study. J Am Soc Nephrol 17:2864-2870

93. Weber S, Taylor JC, Winyard P et al (2008) SIX2 and BMP4 mutations associate with anomalous kidney development. J Am Soc Nephrol 19:891-903

94. Weber S, Landwehr C, Renkert M et al (2011) Mapping candidate regions and genes for congenital anomalies of the kidneys and urinary tract (CAKUT) by array-based comparative genomic hybridization. Nephrol Dial Transplant 26:136-143

95. Wu H, Xu Q, Xie J et al (2017) Identification of 8 novel mutations in nephrogenesis-related genes in Chinese Han patients with unilateral renal agenesis. Am J Nephrol 46:55-63 
Hier steht eine Anzeige.

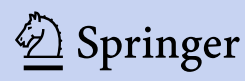

